\title{
High Intensity Polarized Electron Gun
}

\author{
Institution: $\quad$ Massachusetts Institute of Technology \\ Office of Sponsored Programs \\ Street Address: $\quad$ Room NE18-901 \\ 77 Massachusetts Avenue \\ Cambridge, MA 02139 \\ Principal Investigator: $\quad$ Prof. Robert Redwine \\ Phone: $\quad$ (617) $253-9500$ \\ E-mail: $\quad$ redwine@mit.edu
}

Administrative Contact: Michele Hudak

Phone: $\quad$ (617) $324-5382$

E-mail: $\quad$ hudak@mit.edu

Funding Opportunity Announcement Number: DE-FOA-0001556

DOE/Office of Science Program Office: $\quad$ Office of Nuclear Physics

DOE/SC Program Office Technical Contact: Dr. Manouchehr Farkhondeh

DOE Award Number: DE-SC0008741 


\section{Project Description}

\section{Introduction}

The development of highly polarized electron beams has led to many new advances in nuclear and particle physics in recent decades. Polarized electron beams evolved from the development of the laser and semiconducting materials when research in electron spinpolarization from III-V based photoemitters made it possible to produce electron beams with polarization using bulk GaAs photocathodes. Since that time polarized electron sources have been established at numerous facilities worldwide [1-7].

Modern polarized electron sources routinely produce average currents of hundreds of $\mu \mathrm{A}$ with a polarization approaching $90 \%$. This intensity satisfies the requirements of the existing accelerator facilities. New advances in nuclear physics are expected with the development of the high luminosity electron-ion collider (EIC). The concept of such a collider has been discussed in the nuclear physics communities around the world for more than a decade, and is an important element of the 2015 NSAC Long Range Plan. One of the most advanced concepts for an EIC is eRHIC, based on the existing Relativistic Heavy Ion Collider (RHIC) complex located at Brookhaven National Laboratory (BNL) [8].

Two alternative versions of the eRHIC collider have been developed. The ring-ring version is based on construction of an electron storage ring that would intersect the RHIC ion ring in one of the existing interaction regions. The linac-ring version of eRHIC offers the possibility of achieving a higher luminosity. This version is based on the construction of a very high intensity energy recovery linac (ERL). The linac version excludes the possibility of stacking bunches of electrons to achieve very high current. Therefore, the polarized electron source must be able to provide very high average current. In order to achieve a luminosity of $1 \cdot 10^{33} \mathrm{~cm}^{-2} \mathrm{~s}^{-1}$ an average current of at least $I_{a v} \approx 50 \mathrm{~mA}$ is required. Meanwhile, the highest average current produced in existing polarized electron guns on test benches is in the $\mathrm{mA}$ region, but with rather short lifetimes [9-10].

MIT-Bates in collaboration with BNL investigated the possibility of building a very high intensity polarized electron gun using some BNL R\&D funds and a supplement from the DOE Office of Nuclear Physics [11]. Further steps to building and testing a high intensity source have been taken in the last five years with funding from DOE grants DE-SC0005807 and DESC0008741 within the NP accelerator physics R\&D program. This proposal requests funding to continue the work of the last six years and is expected to result in final assembly and testing of a polarized electron gun with unprecedentedly high intensity. This development is crucial for the eRHIC project, as noted in the 2007 and 2015 NSAC Long Range Plans and the November 2009 report of the Electron-Ion-Collider Advisory Committee. 


\section{Approach}

There are three main challenges in the development of a high-intensity polarized electron gun: high average current, high peak current, and heat load on the cathode.

Notably, all three problems can be addressed with increased cathode area. The high average current is the most challenging problem by far. The main reason for photocathode degradation is ion back-bombardment. The electron beam ionizes the molecules of the residual gas in the vacuum system; the ions produced are accelerated in the cathode-anode gap and hit the crystal, damaging the surface. The effect is proportional to the product of the pressure in the gun chamber and the average current.

It is difficult to expect a significant improvement in vacuum conditions over present state-of-the-art installations. However, the effect of the ion bombardment could be mitigated by increasing the emitting area. The number of ions produced will remain the same, but the damage will be distributed over a larger area, increasing the cathode lifetime accordingly. In a simplified picture, the average current that could be extracted from the cathode with the same lifetime is proportional to the emitting area.

In reality the picture is more complicated. The anode hole acts as a defocusing lens for electrons, and as a focusing lens for ions. As a result, ions tend to damage mostly the central area of the cathode. Existing electron guns are using Gaussian shaped laser beams, with the maximum beam intensity near the cathode center, where the ion damage is most significant. For the highintensity gun, it will be beneficial to form a ring-shaped laser beam, so a large fraction of the laser power is applied to the peripheral area of the cathode.

The major obstacle in this approach is to avoid beam losses in the gun and its vicinity. It has been demonstrated that losses as low as $10^{-6}-10^{-5}$ at this intensity could drastically reduce the photocathode lifetime due to gas desorption from the walls. Very detailed simulations including space charge effects have been conducted to design a large area cathode with a ringshaped emission pattern.

Currently-funded work studies the problems of high average current and high heat load on the cathode. The gun produces $\mathrm{CW}$ beam, so the problem of very high peak current can not be studied. However, the gun design is expected to produce up to $0.2 \mathrm{~A}$ of peak current, so some preliminary measurements with a pulsed beam will be conducted this summer. This proposal is aimed at development of high average current pulsed beam, including modifications to the cathode-anode gap and purchase of a suitable laser. We also propose to acquire strained cathodes and perform tests at high polarization in a future year. 


\section{Scope of work}

Preliminary work on the development of a high intensity polarized electron gun was funded through BNL R\&D funds and the DOE Office of Nuclear Physics directly. The gun design includes a gun chamber, a separate chamber for preparation of the cathodes and a loadlock chamber to preserve the ultra-high vacuum conditions in the gun and preparation chambers while loading cathodes into the system. That preliminary phase included two major developments: (1) simulation of the gun and the beam line and (2) design of a cooling system for the cathode, compatible high voltage and vacuum requirements. Additionally, studies of the ioninduced damage patterns were conducted. Results of the preliminary phase are discussed in Section 4.

In Phases 1 (funded through DOE Award DE-SC0005807) and 2 (DOE Award DESC0008741) of the project a polarized electron gun with a large area cathode and active cathode cooling was built and tested. A preparation chamber and a load-lock chamber were built and tested. The beam line and the beam dump were manufactured, installed and tested. Beam line instrumentation and control has been completed. Initial beam tests have been conducted. Results of Phases 1 and 2 are discussed in Section 5. With current funding, we expect to complete $\mathrm{CW}$ beam tests and perform preliminary pulsed beam tests.

In order to complete the project, we need to complete the following tasks:

1. Modify the gun for high peak current operation.

2. Reprocess the gun and bake out the entire system.

3. Conduct high intensity, high peak current tests.

4. Assuming the beam tests are successful, procure strained cathodes, which produce higher electron beam polarizations than bulk GaAs crystals.

With this proposal, we request funding for these four items, as outlined in the Work Plan in Section 6.

\section{Preliminary Phase results}

\subsection{Ion damage studies}

Measurements were conducted with a previously existing test beam line described in [6]. A fiber-coupled diode laser with a wavelength of $\lambda=808 \mathrm{~nm}$ was used for photoemission. An axicon (conical lens) in conjunction with a focusing lens formed a ring-shaped laser beam at the location of the cathode. With the axicon removed, focusing lenses formed a point-to-point focus between the output of the laser fiber and the cathode, resulting in a very small laser spot. The last lens was mounted on a translation stage for a precise translation in both transverse directions, which allowed scanning the surface of the cathode to map the QE of the crystal. 
The measurements were conducted in different emitting configurations: very small centered Gaussian beam, the same Gaussian beam placed in the corner of the cathode, large Gaussian beam, and ring-shaped beam. The QE map was re-measured after each run. The measurements confirmed the conclusion that most of the ion-related damage occurs at the center of the cathode. When the ring-shaped beam was used, the damage in the center of the crystal, where the laser power was negligible, was significantly higher than the damage in the peripheral part of the cathode, where most of the laser power was applied. The results of these measurements have been reported in [12].

\subsection{Gun and beam line simulation}

The $120 \mathrm{kV}$ DC gun was designed to be operated with a current from 0 to $100 \mathrm{~mA}$. The anode-cathode gap is $100 \mathrm{~mm}$ and the maximum electric field on the surface of the cathode is about $39 \mathrm{kV} / \mathrm{cm}$. The gun features a biased $(1 \mathrm{kV})$ anode in order to repulse ions produced in the beam line.

A ring-shaped beam is expected to be used in the gun. However, the exact shape of the beam can't be guaranteed. Optical misalignments and non-uniformity of the Quantum Efficiency (QE) of the cathode may lead to deformation of the beam shape. In order to include these factors in the analysis, three different beam shapes were studied: ring-shaped, Gaussian and flat distributions. The SAM code [13] was used for the simulations.

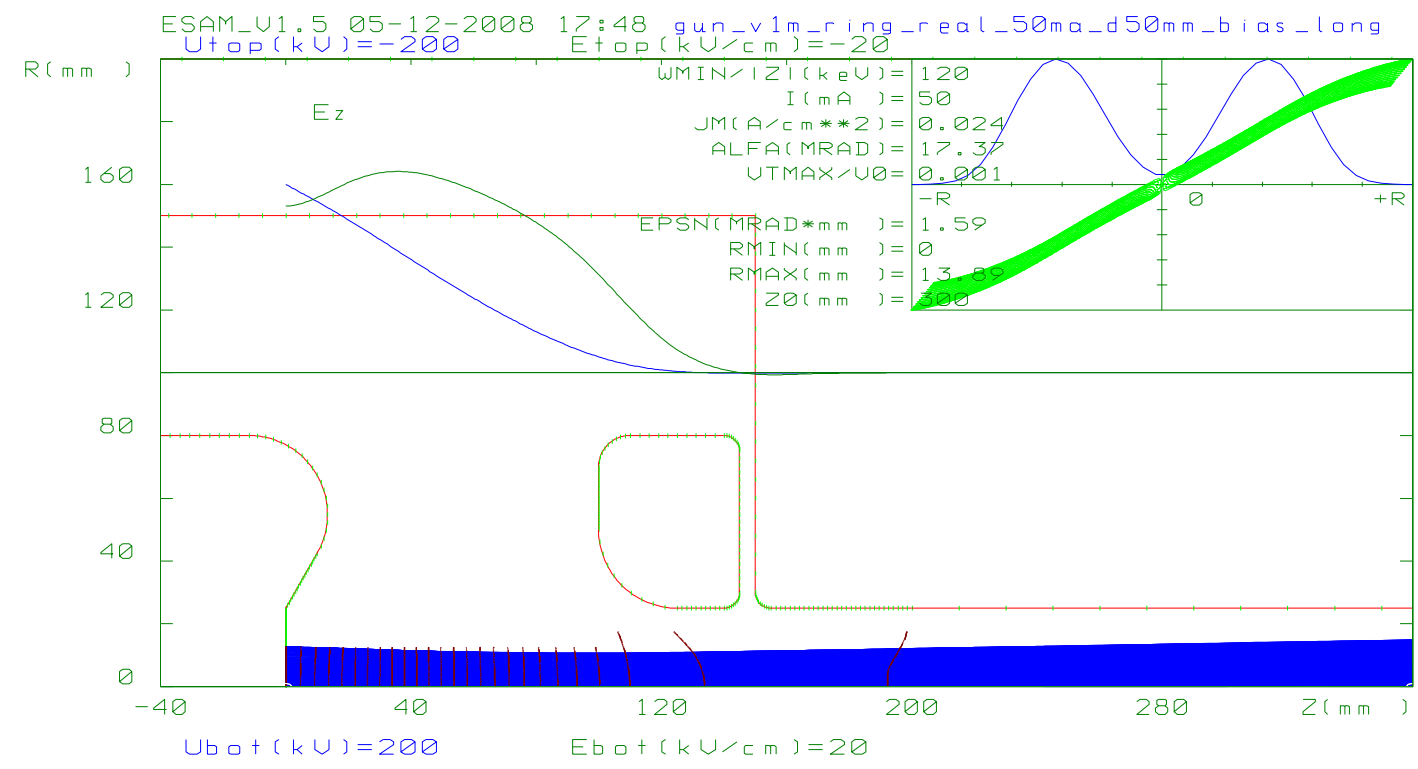

Figure 1. $120 \mathrm{kV}$ gun simulation for a ring-shaped beam. Shown in the main window: equipotentials (red), axial distributions of electric field (green) and of potential (blue), and electron trajectories (solid blue). In the right upper corner, the distribution of current density (blue) and phase portrait (green) of the ringshaped beam on the gun exit. 
The propagation of $100 \mathrm{~mA}$ of electrons through the gun is shown in Fig. 1. The normalized beam emittance at the exit of the gun varied from 1.3 to $2.7 \mathrm{~mm} \cdot \mathrm{mrad}$, depending on the beam shape (the largest emittance was for the flat distribution).

The beam line layout can be seen in Fig. 2. The main purpose of the beam line is separation of the Ultra High Vacuum (UHV) conditions in the gun from the inferior vacuum conditions of the beam dump. The beam line consists of two $90^{\circ}$ dipole magnets and a doublet of solenoidal lenses between these dipoles. The third solenoidal lens is used to increase the size of the beam in the dump in order to reduce the power density. The dipole magnets have the same focusing properties in both directions in order to maintain the axisymmetric shape of the beam. The lenses have a large internal diameter $(90 \mathrm{~mm})$ and produce very linear focusing.

The tails of the beam have been calculated to high accuracy in the locations where the beam size is maximal (entrances into the dipole magnets and solenoidal lenses). Space charge effects are most important for the Gaussian beam, where the charge density is greater. Space charge effects increase the beam emittance (for a Gaussian beam, the emittance grows from 1.3 to $2.9 \mathrm{~mm} \cdot \mathrm{mrad}$ at the end of the beam line at a current of $100 \mathrm{~mA}$ ). However, the space charge effects hardly affect the tails of the beam in any configuration.

MAC3D_2.0 14-12-2008 13:54 beamline_v4_losses_ring

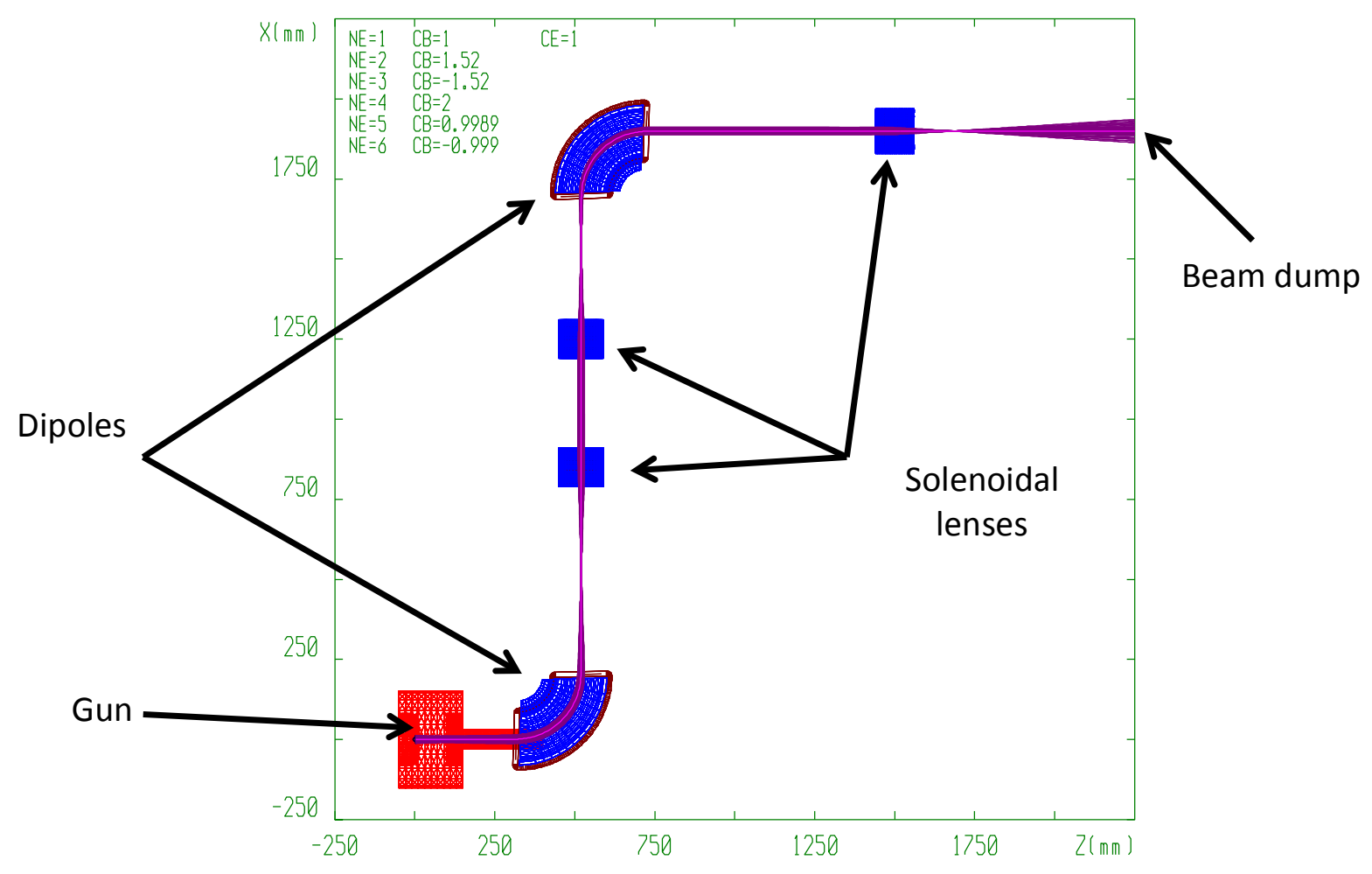

Figure 2. General layout of the beam line. 
Beam propagation through the beam line has been simulated for all three distributions. Since it would be too compute-intensive to simulate losses of the order of $10^{-6}$ directly, the following approach was used. For a given beam configuration, the electrical and magnetic fields were calculated, including the fields produced by the beam itself. In the next step, only electrons emitted from the very edge of the cathode were considered (only these electrons could contribute to beam losses). Since the emitting current density is rather low at the edge of the cathode (except for the flat distribution), a very significant gain in statistical accuracy was achieved.

Simulations demonstrated that everywhere in the beam line, losses of the order of $10^{-6}$ happen at apertures of less than $20 \mathrm{~mm}$. The only exception is the entrance into the first dipole for the Gaussian beam, where this critical aperture is about $23 \mathrm{~mm}$. Since the actual apertures of the beam line are about $30 \mathrm{~mm}$, no losses of the order of $10^{-6}$ are expected.

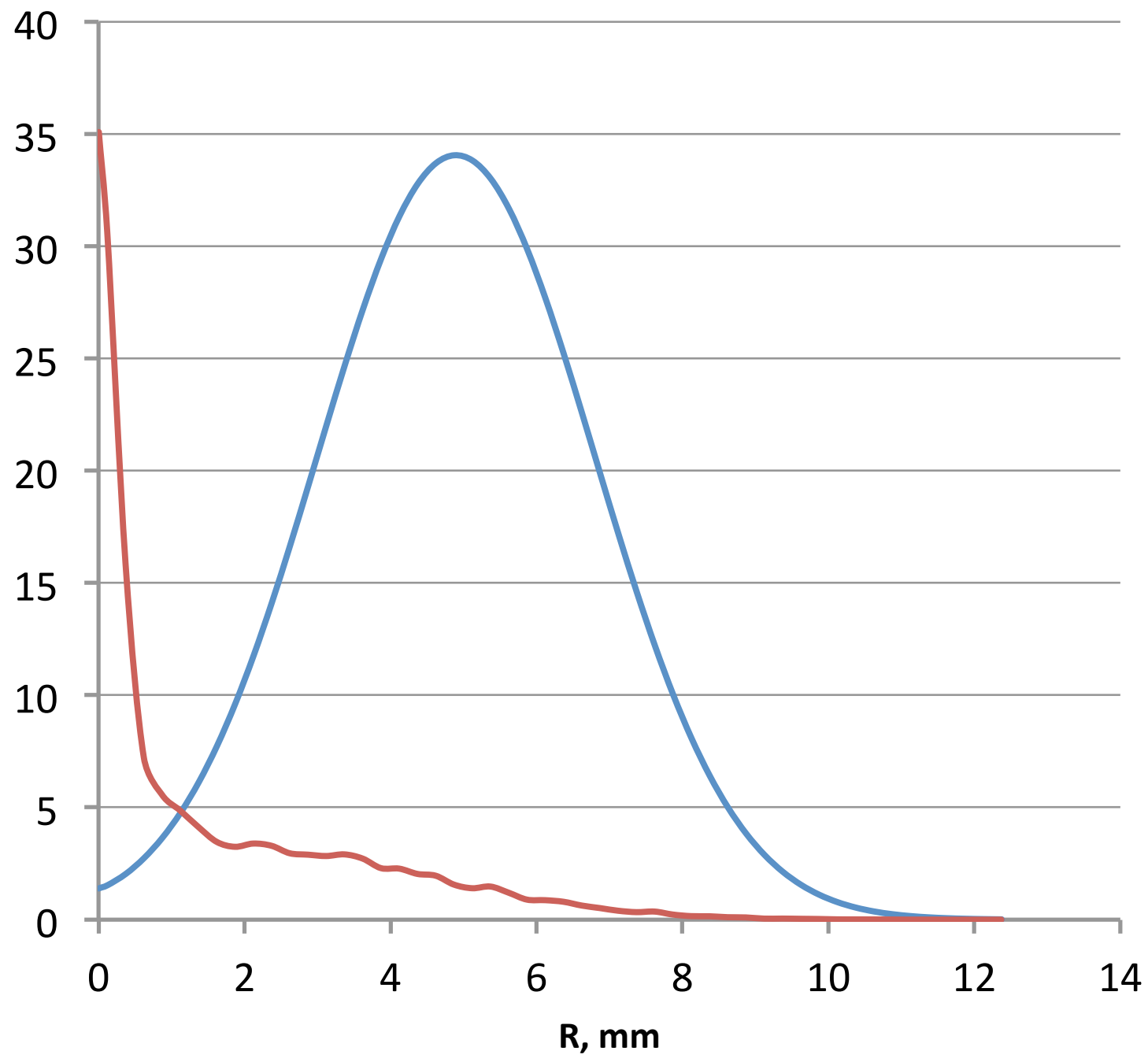

Figure 3. Electron current density (blue, $m A / \mathrm{cm}^{2}$ ) and ion power density (red, a.u.) on the cathode. 
Additionally, the ion trajectories have been calculated and the expected damage pattern estimated. Calculations of the trajectories of ions produced in the cathode-anode gap demonstrated that ions produced close to the anode (which have the highest energy and produce the most significant damage) are focused into the center of the cathode, and their footprint on the cathode has a rather small overlap with the emitting pattern of the ring-shaped electron beam. The gun geometry and the emission pattern have been optimized to reduce the overlap of the emission pattern and the damage pattern. Fig. 3 shows the emission pattern and ion damage pattern with a ring-shaped beam.

\subsection{Test chamber design and fabrication}

The conceptual design of the test chamber is shown in Figure 4. The test chamber was designed as a prototype of the actual gun, utilizing the same mechanism for vacuum manipulation as planned for the real gun chamber. The GaAs crystal installed in the molybdenum puck is delivered into the test chamber with a magnetically-coupled manipulator.

The cathode assembly consists of the cathode electrode, heat exchanger and field shield. It is suspended on three ceramic pipes that insulate the assembly from ground. One of the pipes is used to deliver HV to the cathode, the other two serve as conduits for the cooling agent. An additional ceramic pushing rod installed on the Linear Transfer Mechanism (LTM) allows the cathode electrode to be lowered, separating it from the heat exchanger. The cathode puck is inserted into the gap with the manipulator. Then the cathode assembly is raised, pressing the puck to the heat exchanger. Cone-to-cone surfaces on the puck and the heat exchanger center the puck and provide good thermal contact. The field shield protects the unpolished inside parts of the assembly from an electric field. 


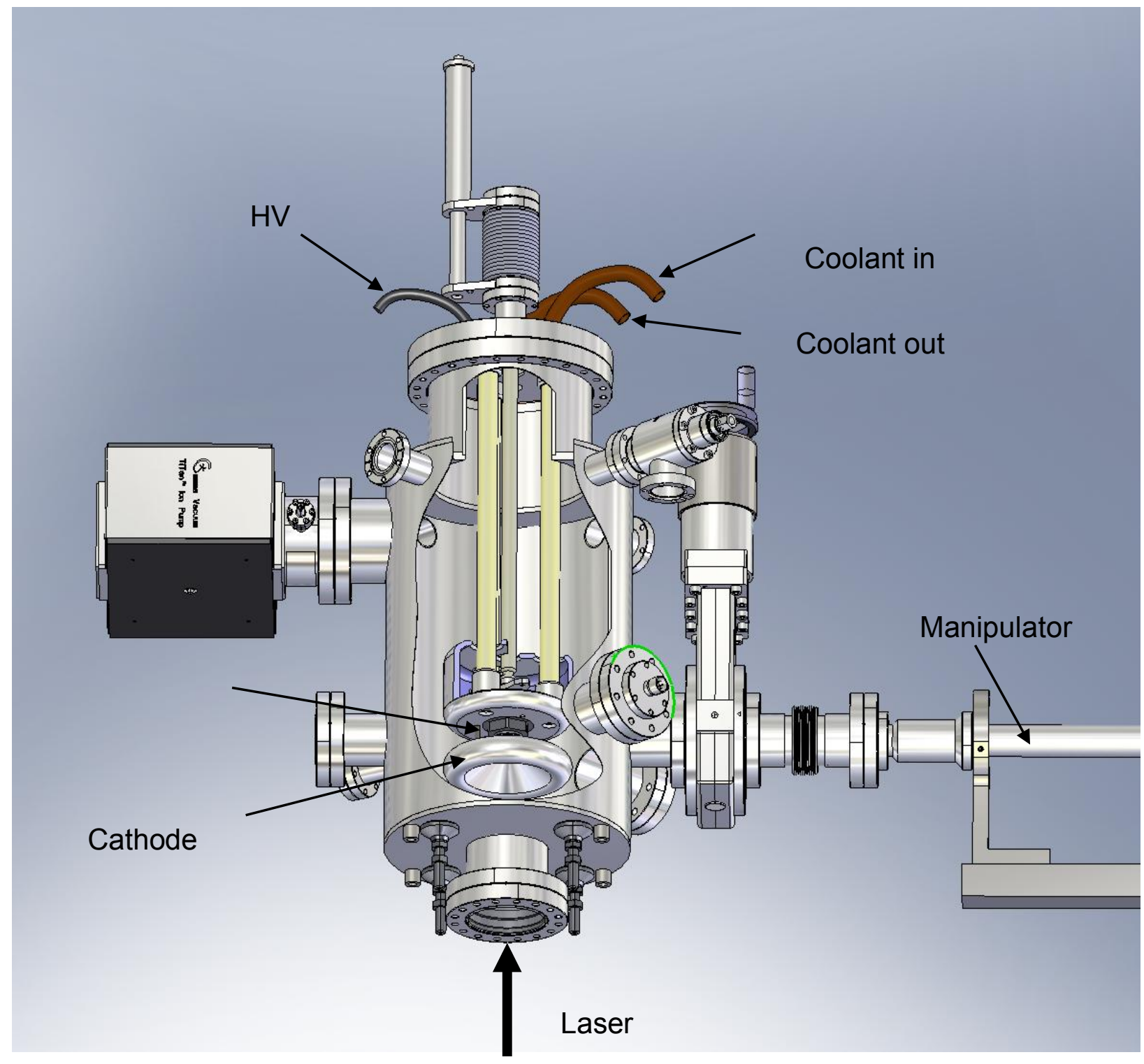

Figure 4. Test chamber.

The heat exchanger consists of two copper plates brazed together; a spiral channel machined in the plates conducts the cooling agent, providing an effective heat transfer. Fluorinert has been chosen as the cooling agent. This liquid has an extremely low electrical conductivity, a high electrical strength and acceptable viscosity and thermal conductivity. The cooling agent circulates through a chiller with adjustable flow and temperature.

The test chamber is equipped with several view ports to monitor vacuum manipulations. Illumination is provided with halogen bulbs installed inside the vacuum chamber. 
Designing the test chamber as a prototype of the gun proved to be very useful. Several minor drawbacks were discovered during the assembly (inconvenient flange arrangement, poorly designed fixture for the pushing rod, lack of a proper pathway for the wire to bias the anode, and so on). These problems have been corrected in the gun design.

\subsection{Test results}

The first tests demonstrated very reliable vacuum manipulation. Transfer of the puck with a crystal into and out of the test chamber was performed a dozen times. The manipulator engages and disengages the puck at the cathode assembly reliably. The cone-to-cone centering system works very well. For test purposes the puck was disengaged from the manipulator several millimeters off the center, and yet it was centered perfectly when the cathode electrode was raised. The viewports provide good observation of the manipulation. Halogen lights provide excellent illumination. They give more than enough light, even with the voltage significantly lower than nominal voltage, so one may expect a very long lifetime of these bulbs. Since four bulbs have been installed inside the chamber, we never expect to have a need to open the vacuum chamber to replace a burned-out bulb.

Full-scale UHV tests were not performed due to absence of the required pumps. Nevertheless, even the unbaked test chamber was pumped down to a rather good vacuum. With only one $120 \mathrm{l} / \mathrm{s}$ ion pump equipped with a NEG, a vacuum of about $5 \cdot 10^{-9}$ torr was achieved routinely.

The gun was successfully processed to $120 \mathrm{kV}$. However, multiple electrical breakdowns were observed during HV processing. These breakdowns are not dangerous for the GaAS crystal since processing takes place without the crystal puck in the gun. The source of the breakdowns was identified. Some electrons originating from field emission during processing accumulated on the ceramic pipes and finally produced a potential so great that a breakdown occurred. Potentially such breakdowns could punch through the ceramic, resulting in vacuum failure, so it is very desirable to avoid them.

Several sources of field emission capable of producing such electrons were identified. The field shield was modified to reduce the electrical field in these locations significantly. The modified shield eliminated the electrical breakdowns completely.

The cathode cooling tests were conducted with a thermocouple attached to the outer edge of the molybdenum puck. This part of the puck is the farthest from the cooling surfaces and it is expected that the temperature of the thermocouple is close to the temperature of the crystal. The tests were conducted in vacuum.

The ring-shaped laser beam was directed to the crystal through a viewport at the bottom

of the test chamber. The laser was able to produce up to $38 \mathrm{~W}$ of laser power. Taking into account losses in the optics and the viewport, the maximum laser power delivered to the crystal was about $34 \mathrm{~W}$. 


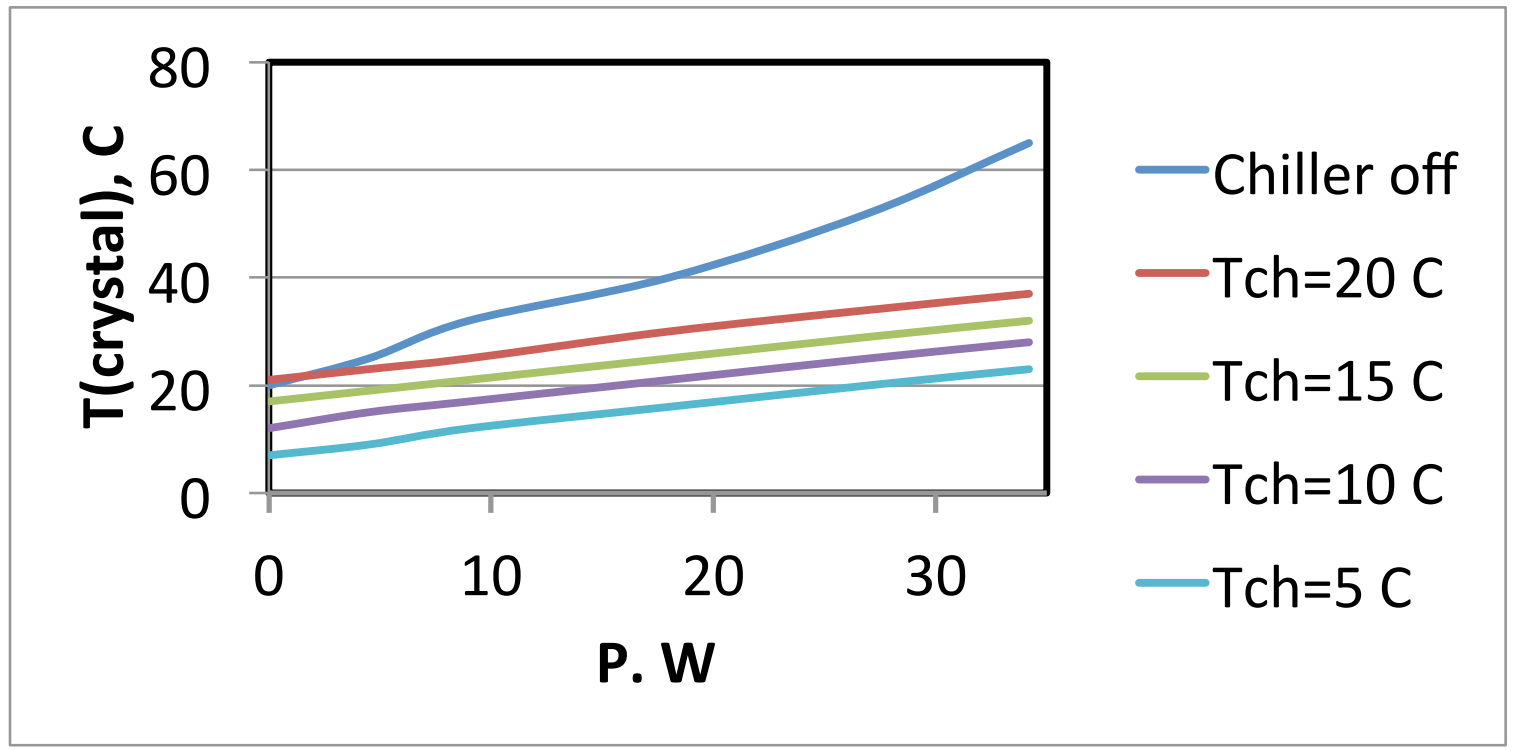

Figure 5. Cathode cooling test results: temperature of the cathode as a function of laser power at different set points of the chiller (Tch).

Results of the tests are presented in Fig. 5. The temperature of the cooling agent (Tch) was varied from $5^{\circ} \mathrm{C}$ to $20^{\circ} \mathrm{C}$. The temperature difference between the cooling agent and the thermocouple was about $17^{\circ} \mathrm{C}$ at the maximum laser power. Therefore, by setting the chiller set point to $5^{\circ} \mathrm{C}$, we were able to keep the crystal temperature at about $22^{\circ} \mathrm{C}$ at this laser intensity.

\section{Phase 1 and 2 results}

\subsection{Gun chamber}

The design of the gun chamber is very similar to the design of the test chamber described in section 4.3 and shown in Figure 4. The gun implements a so-called "inverse geometry". There are no outside ceramics; the gun chamber is manufactured from stainless steel. The cathode assembly is suspended on three long ceramic tubes. Two of these tubes serve as pipes to deliver cooling agent to and from the cathode. Fluorinert is used as a cooling agent. This liquid has virtually zero conductivity and very good electrical strength. The third tube serves as a conduit for the HV cable. The working voltage of the cathode is $120 \mathrm{kV}$.

The GaAs crystal is mounted on a molybdenum puck with a tantalum cup pressing it to the puck. An indium foil is inserted between the puck and the crystal. During the first activation the foil melts and solders the crystal to the puck providing a very good thermal connection. An additional ceramic rod attached to a Linear Transfer Mechanism (LTM) at the top of the chamber moves the cathode in the vertical direction, allowing a gap to open between the cathode and the heat exchanger. The puck with a crystal is inserted into this gap through the side port using a 
magnetically-coupled manipulator. The conical shape of the interface between the puck and heat exchanger ensures self-centering and a good thermal connection (see Fig.6).

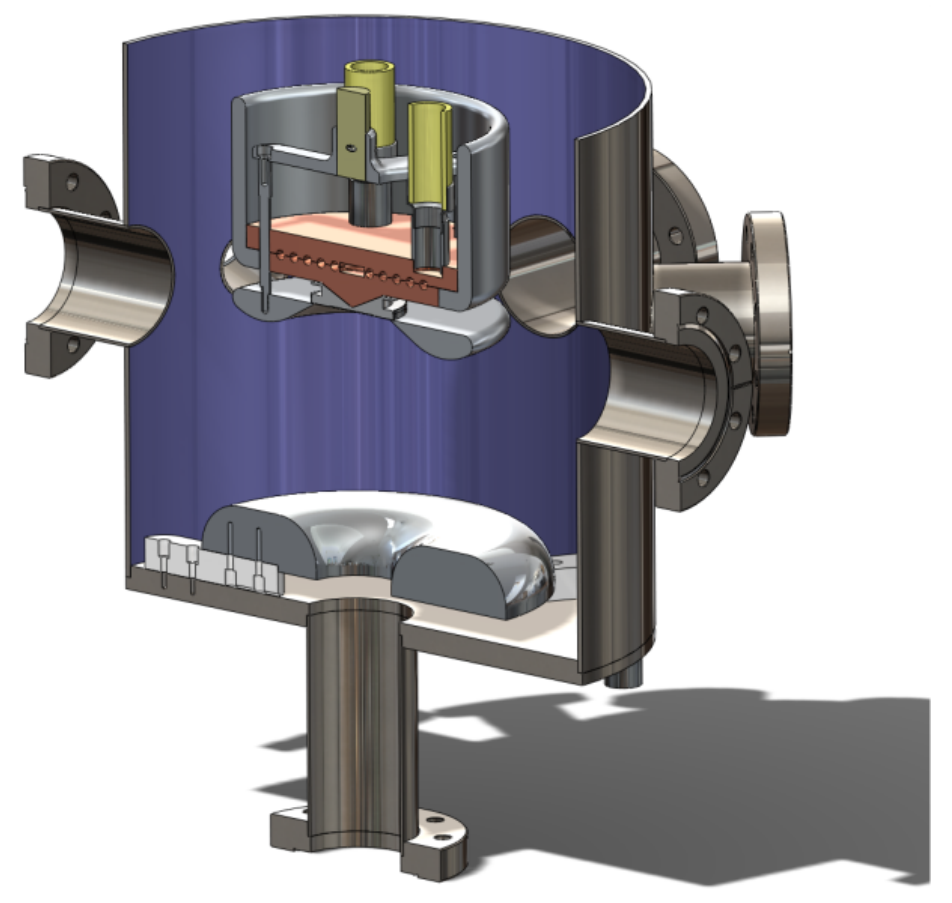

Figure 6. Anode and cathode assembly.

The gun chamber is pumped by a $100 \mathrm{l} / \mathrm{s}$ ion pump and five $400 \mathrm{l} / \mathrm{s}$ NEGs. The chamber walls are made from thin $(3 \mathrm{~mm})$ stainless steel to reduce wall outgassing. The main body and all large metal parts were prebaked at $400^{\circ} \mathrm{C}$. After that the chamber was fully assembled and baked at $200^{\circ} \mathrm{C}$. The resulting vacuum is in the high 12 -scale, dominated by hydrogen.

The cathode assembly is surrounded by a polished field shield to prevent field emission. The gun is processed to $150 \mathrm{kV}$. After the processing there is no sign of activity (measurable dark current or vacuum excursions) at the working voltage of $120 \mathrm{kV}$. The anode is disconnected from ground potential and biased to $1 \mathrm{kV}$ in order to reflect the ions that are produced outside the cathode-anode gap and trapped in the electron beam.

\subsection{Preparation chamber}

The molybdenum pucks equipped with crystals are moved from the load-lock into the preparation chamber with a magnetically-coupled manipulator. The preparation chamber carousel can hold up to three pucks. The preparation chamber has two heat-cleaning stations and two activation stations. Each heat cleaning station is equipped with a PBN heater, a thermocouple for reference measurements and a view port for the pyrometer. The activation 
stations are equipped with cooling rods, cesium dispensers, an NF3 leak valve and windows for laser light. The cooling rods can be biased to apply negative voltage to the crystals.

Activated crystals are moved into the gun chamber using a similar manipulator. The loadlock, preparation and gun chambers are all equipped with view ports to observe and control the vacuum manipulation, with halogen bulbs inside for illumination.

\subsection{Load-lock chamber}

The load-lock chamber has a rack that can hold can hold up to four molybdenum pucks. After pucks are loaded and good vacuum conditions are achieved in the load-lock chamber, the pucks are moved into the preparation chamber with a magnetically-coupled manipulator.

\subsection{Vacuum manipulation and crystal activation}

GaAs crystals routinely have been transported from the load-lock into the preparation chamber, and between the preparation chamber and the gun chamber.

GaAs crystals have been activated in the preparation chamber, and a rather high QE $(\sim 2 \%$ at $\lambda=805 \mathrm{~nm}$ ) has been measured.

\subsection{Beam line}

The beam line consists of the two $90^{\circ}$ dipole magnets, several focusing solenoids, steering coils and a beam dump. The beam dump is equipped with a flip target and current monitor. The beam propagation in the beam line was carefully modeled to ensure that no sizable beam losses occur in the vicinity of the gun chamber. See Fig. 7 for a solid model "view" of the load-lock, preparation and gun chambers as well as the first segment of the beam line. 


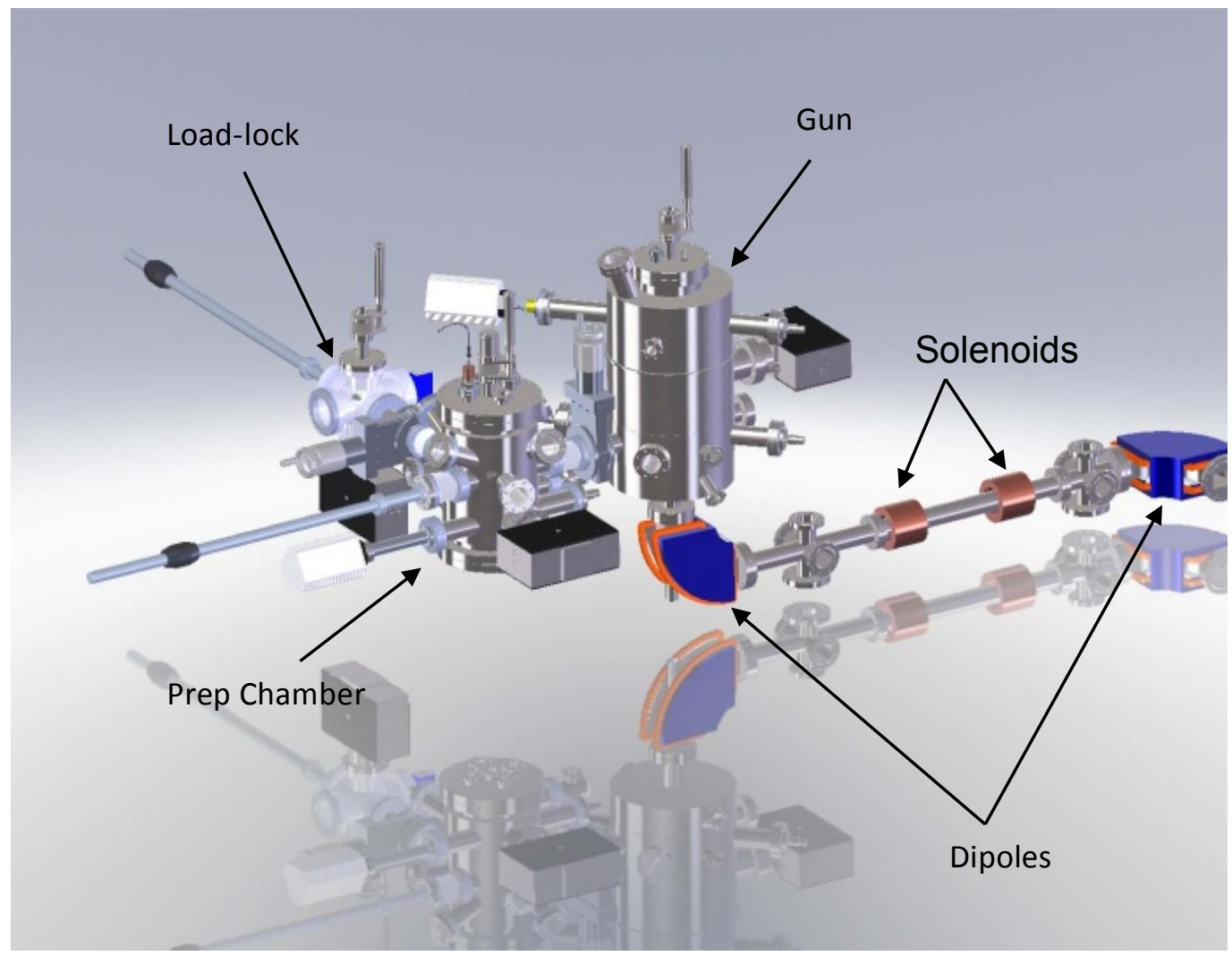

Figure 7. Solid model of the load-lock, preparation and gun chambers and the first segment of the beam line with main components indicated.

Intensive computer simulations of the heat transfer to the unbiased beam dump were performed to understand whether the dump will overheat with a current up to 50 $\mathrm{mA}$ (Fig. 8). Based on these simulations, it appears this dump may be suitable even for high current running. The unbiased beam dump has been built. 


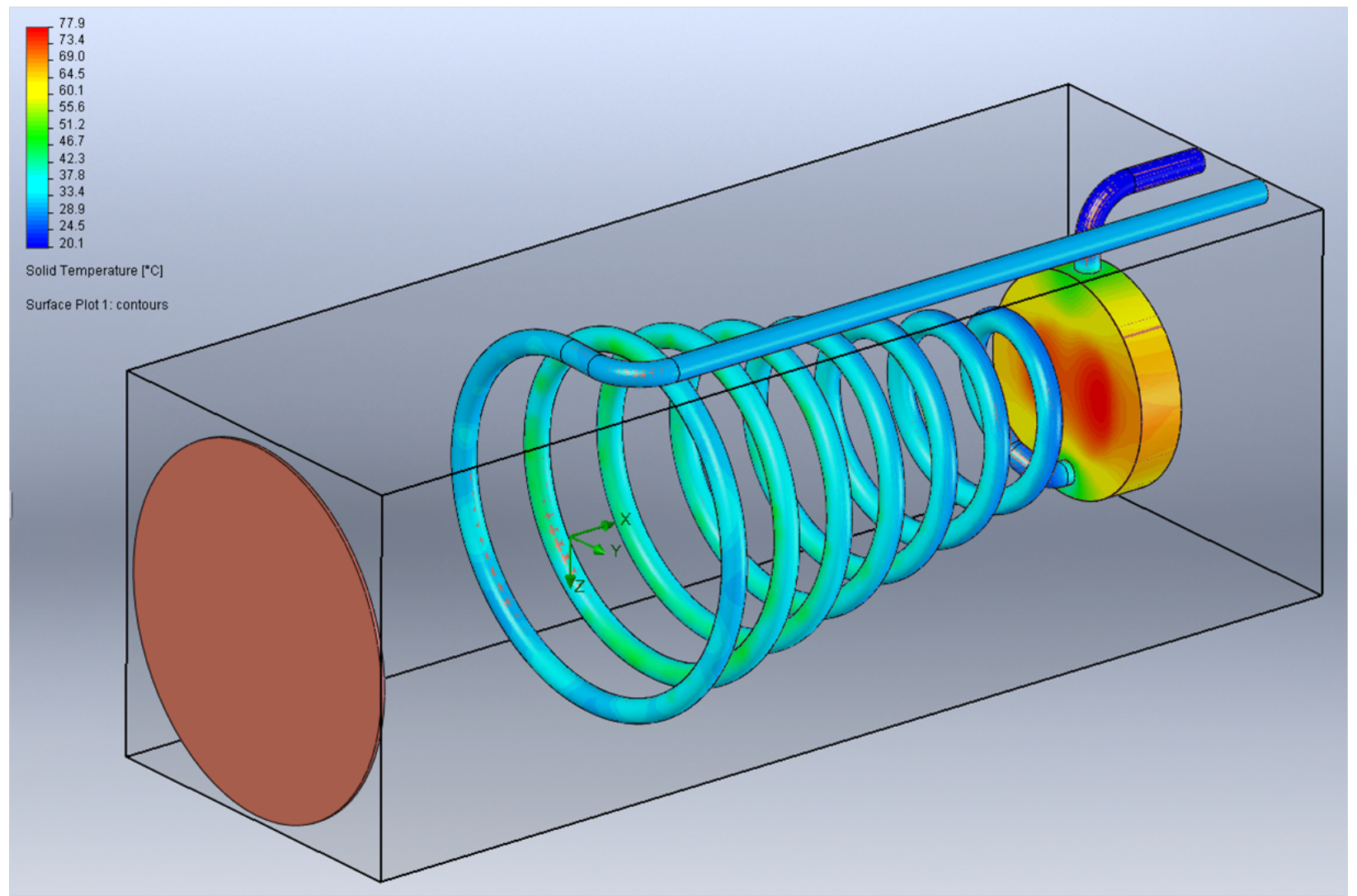

Figure 8. Computer simulation of temperatures in the unbiased beam dump with a current of $50 \mathrm{~mA}$ (beam enters from the left). The disk on the left represents the interface to the beam line vacuum system. The conical cooling loop intercepts the majority of the ring-shaped beam. The tails of the beam are stopped on the disk at the right. Inlet water temperature is $20 \mathrm{C}$, and the calculated maximum temperature is less than $80 \mathrm{C}$.

\subsection{Biased beam dump}

Our calculations demonstrated that an unbiased beam dump should be sufficient for this project. However, there is a possibility that the outgassing in the dump will be too great and will affect the vacuum conditions in the gun chamber, and thus reduce the lifetime of the cathode. In this unlikely event, we would have to replace the unbiased beam dump with a biased one. The conceptual design of the biased dump had been developed.

The biased beam dump is a rather cumbersome and expensive device, and at this time we do not request funding to build it. However, if the unbiased beam dump fails to maintain good vacuum conditions in the gun as we perform high-current testing, we will request this funding in a future proposal. 


\subsection{Preliminary beam tests}

We have run low intensity (several nA) beam from the gun through the beam line. The beam was successfully guided through both dipoles, and detected on flip targets. Both Gaussian and ring-shaped emission patterns have been used, and the measured beam shapes in the target locations were very consistent with the simulation results (see Figure 9)

Preliminary results from the studies were reported in [14]. However, we found the lifetime of the cathode to be very short. We investigate possible causes of the short lifetime.

1. We suspected a leak in the cooling system. Even a very small amount of Fluorinert in the vacuum system will poison the cathode very quickly. It is very difficult to observe Fluorinert, since the molecules are too large to be detected by mass spectrometry. Despite their size, the Fluorinert molecules are very mobile and can penetrate through very narrow cracks. The gun was vented and rebaked to make certain that all Fluoirinert evaporated. The lifetime improved dramatically. The beam was reestablished all the way through the beam line into the beam dump. However, we noted that when the valve to the beam line was opened prior to performing beam tests, the dark lifetime dropped significantly, indicating insufficiently good vacuum in the beam line. The RGA scan showed that, although the hydrogen partial pressure in the beam line was only slightly higher than in the gun chamber, we could distinctly observe traces of other species (masses $16,18,28$ ) that are virtually invisible in the gun chamber.

2. The beam line doesn't have as many pumps as the gun chamber. Additionally, it has solenoidal lenses that could not be removed during bake out. As a result, we baked the beam line very conservatively to avoid damaging the lenses, and so the base pressure of the beam line was consequently higher than that of the gun chamber. We installed three additional NEG pumps on the beam line and performed a more aggressive bake in order to improve the vacuum conditions in the beam line. We saw significant improvement in the beam line vacuum. However, the dark lifetime of the cathodes remained low.

3. Each cathode has an indium foil placed between the GaAs crystal and the molybdenum puck, soldered together by the first activation for a good thermal connection. We have observed that the indium foil is too thick; the excess indium leaks into the gap around the edge of the crystal and touches the front face of the crystal. We believe that the surface diffusion from indium (it is not a good metal for UHV conditions) caused the observed short lifetime.

A new set of cathodes has been prepared - one cathode with a much thinner indium foil, and another without any foil at all. The new cathodes have been loaded into the preparation chamber and new lifetime and beam tests are about to begin.

Using existing funding, we expect to complete the high intensity $\mathrm{CW}$ beam tests in June 2016, and preliminary pulsed beam tests by August 2016. The main goal of the preliminary pulsed beam tests is to establish how the space charge of the high peak current beam affects beam propagation, beam losses and cathode lifetime. 


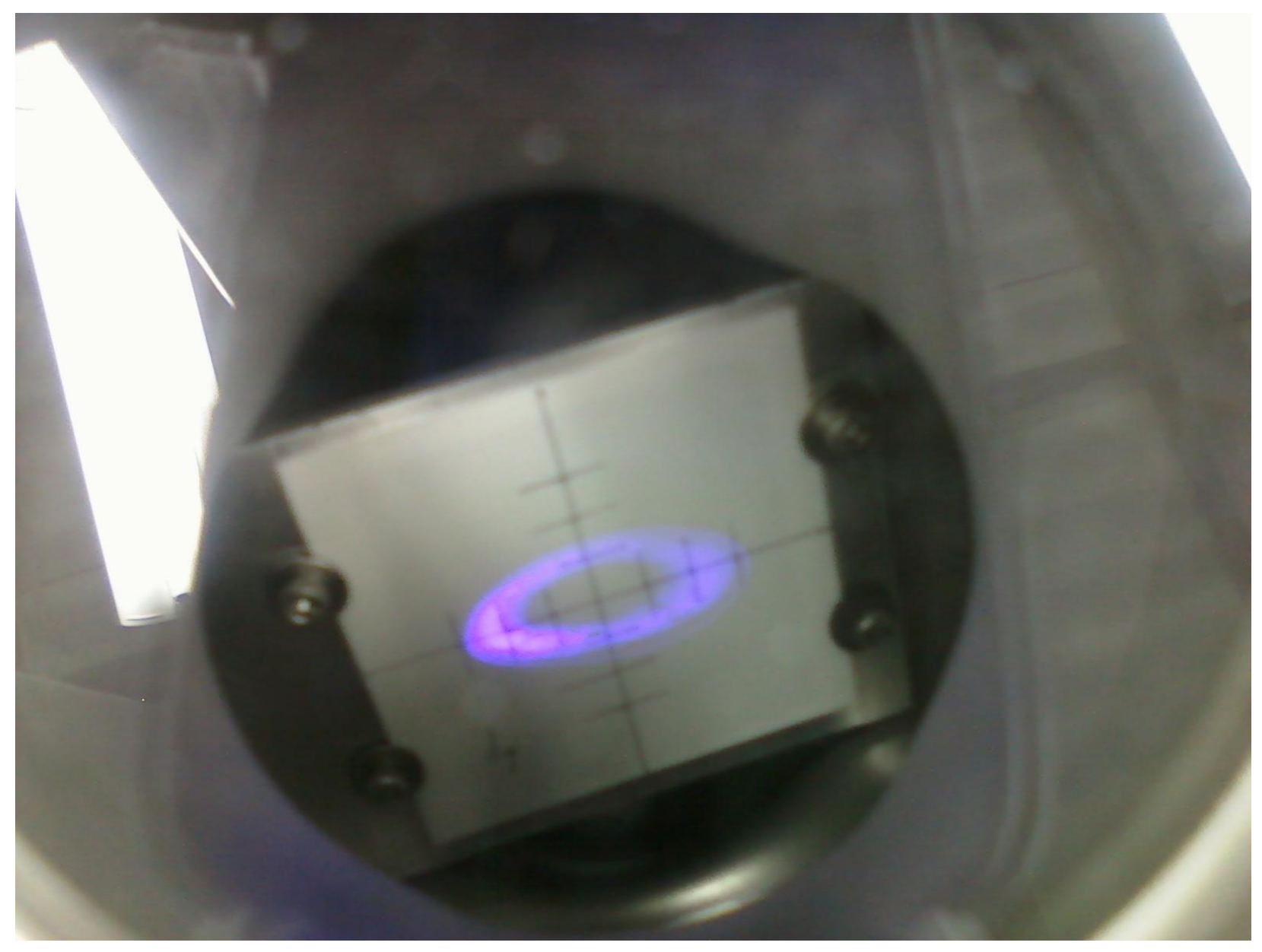

Figure 9. Ring-shaped electron beam on $\mathrm{BeO}$ target after the second dipole magnet.

\section{Work plan}

The short lifetime of the cathodes, combined with excellent vacuum conditions in the gun, indicates the presence of some contamination. The first task is to find and remove the source of that contamination. We have already investigated the possibility of Fluorinert leakage into the gun chamber, and we will investigate all other possible sources (indium foil, traces of polishing paste on titanium caps, details of crystal etching and preparation). Once the source of contamination is detected and removed, we'll conduct beam tests and measure the cathode lifetime at different currents.

Once these tests are successful, with the funding proposed here, we will modify the gun for high peak current operation. The major modification will be a reduction of the cathode-anode gap to minimize the space charge effects. If the preliminary tests in the summer of 2016 indicate other useful modifications that could be implemented in the gun, preparation chamber, or beam line to maximize beam current and/or lifetime (either CW or peak), those can be done at the 
same time. After these modifications the gun will be reprocessed and the whole system will be re-baked. When good vacuum conditions have been established in the whole system, we will conduct high intensity, high peak current tests.

These tests will be conducted with convenient GaAs cathodes. If the tests produce promising results, then strained superlattice photocathodes should be tested. These photocathodes produce a higher electron beam polarization, which results in a higher figure of merit for experiments using a polarized electron beam. However, the procurement of such cathodes could be a very long process; thus we would seek funding for procurement and testing in 2017.

\section{Milestones}

Assuming that the funds become available August 15, 2016, we plan to achieve the following milestones:

1. Modifications to the gun for high peak current, and to the rest of the system to maximize current and/or lifetime, will be completed in December 2016.

2. The modified system will be ready for operation (gun re-processed, system re-baked, vacuum conditions established) in March 2017.

3. High peak current tests will be completed in July 2017.

4. The final report will be written in August 2017.

\section{Budget}

The expenses for this proposal include:

\begin{tabular}{|l|lr|}
\hline \multicolumn{1}{|c|}{ ITEM } & \multicolumn{1}{c|}{ COST (K\$) } & \\
\hline Equipment to be added to existing system: & & \\
\hline Gun modification & 10.0 & $\mathbf{2 9 . 0}$ \\
\hline New laser & 4.0 & \\
\hline Other items & 15.0 & $\mathbf{1 0 . 3}$ \\
\hline Materials and supplies & & $\mathbf{3 . 0}$ \\
\hline Travel & & \\
\hline
\end{tabular}

Manpower effort for the year includes 2.4 man-months technician, 2.4 man-months engineer/designer and 4.8 man-months physicist, leading to a funding request of $\$ 278,000$. The 
cost assumes the biased beam dump does not need to be built. If the biased beam dump is needed, we estimate the additional cost at $\$ 110,000$, which would be requested in 2017. A 2017 request would also include procurement of superlattice photocathodes, and manpower of 2 manmonths of technician, 2 man-months of engineer/designer and 4 man-months of physicist to prepare and install the photocathodes and run beam tests. The 2017 request would total roughly $\$ 310,000$ with the biased beam dump, or $\$ 200,000$ without it.

\section{Conclusion}

With funding proposed here, we will modify the gun for high peak current operation and complete the high peak current tests. Earlier phases of this development project have shown promise for very high intensity beam. This development is crucial for the eRHIC project, as noted in the 2007 and 2015 NSAC Long Range Plans and the November 2009 report of the Electron-Ion-Collider Advisory Committee. eRHIC requires average polarized electron currents on the order of $25 \mathrm{~mA}$. 


\section{Appendix 1: Biographical Sketches}




\title{
Robert P. Redwine
}

\author{
Director, Bates Linear Accelerator Center \\ Professor of Physics \\ Massachusetts Institute of Technology
}

\section{EDUCATION:}
1969 A.B. Physics
Cornell University
1973 Ph.D. Physics
Northwestern University

\section{Professional Experience:}

Director, Bates Linear Accelerator Center, MIT

2006 - Present

Dean for Undergraduate Education, MIT

2000 - 2006

Director, Laboratory for Nuclear Science, MIT

$1992-2000$

Professor of Physics, MIT

1990 - Present

Visiting Associate Professor of Physics, Princeton University

Spring 1989

Visiting Associate Professor of Physics, Rutgers University

Fall 1988

Associate Professor of Physics, MIT

$1982-1990$

Assistant Professor of Physics, MIT

$1979-1982$

Staff Scientist, Los Alamos National Laboratory

$1977-1979$

Forschungsassistent, University of Berne, Switzerland

$1974-1975$

Research Associate, Los Alamos National Laboratory

1973 - 1974,

$1975-1977$

\section{Selected ACAdemic Awards:}

Fellow, American Association for the Advancement of Science

Fellow, American Physical Society

\section{SyNERGISTIC ACTIVITIES:}

- Member, AAAS Physics Section Nominating Committee

- Chair, APS Division of Nuclear Physics Committee on Funding Issues

- Indiana University Center for the Exploration of Energy and Matter Advisory Committee

- Board of Directors, Brookhaven Science Associates

- Nuclear Science Advisory Committee - Long Range Planning Committee
2009 - 2012

2008 - present

2011 - present

2006 - present

2001, 1995, 1989 and 1983

\section{Selected Publications:}

"The role of mesons in the electromagnetic form factors of the nucleon" (with C.B. Crawford et al. (The BLAST Collaboration)), Phys. Rev. C82, 045211 (2010).

"The BLAST experiment" (with D. Hasell et al. (The BLAST Collaboration)), Nucl. Inst. \& Meth. A603, 247 (2009). 
"Charge Form Factor of the Neutron at Low Momentum Transfer from the ${ }^{2} \overrightarrow{\mathrm{H}}\left(\overrightarrow{\mathrm{e}}, \mathrm{e}^{\prime} \mathrm{n}\right){ }^{1} \mathrm{H}$ Reaction" (with E. Geis et al. (The BLAST Collaboration)), Phys. Rev. Lett. 101, 042501 (2008).

"Measurement of the proton electric to magnetic form factor ratio from ${ }^{1} \overrightarrow{\mathrm{H}}\left(\overrightarrow{\mathrm{e}}, \mathrm{e}^{\prime} \mathrm{p}\right.$ )" (with C.B. Crawford et al. (The BLAST Collaboration)), Phys. Rev. Lett. 98, 052310 (2007).

"Pion nucleus interactions", T. S. H. Lee and R. P. Redwine, Ann. Rev. Nucl. Part. Sci. 52, (2002) 23.

"Measurement of the beam-spin azimuthal asymmetry associated with deeply-virtual Compton scattering" (with A. Airapetian et al. (The HERMES Collaboration)), Phys. Rev. Lett. 87, 182001 (2001).

"The flavor asymmetry of the light quark sea from semi-inclusive deep-inelastic scattering" (with K. Ackerstaff et al. (The HERMES Collaboration)), Phys. Rev. Lett. 81, 5519 (1998).

"Evidence of initial state interactions in multi-nucleon pion absorption" (with D. Androic et al. (The LADS Collaboration)), Phys. Rev. C53, R2591 (1996).

"Large-solid-angle study of pion absorption on ${ }^{3} \mathrm{He}$ " (with T. Alteholz et al. (The LADS Collaboration)), Phys. Rev. Lett. 73, 1336 (1994).

"Tensor polarization in elastic electron-deuteron scattering in the momentum transfer range $3.8<\mathrm{q}<4.6$ $\mathrm{fm}^{-1}$ " (with M. Garçon et al.(The T20 collaboration)), Phys. Rev. C49, 2516 (1994).

\section{COLlaborators AND CO-EDITORS}

Ricardo Alarcon, Arizona State University; Doug Beck, University of Illinois - Urbana/Champaign; Betsy Beise, University of Maryland; Vince Cianciolo, ORNL; Chris Crawford, University of Kentucky; Brad Filippone, Caltech; Haiyan Gao, Duke University; Paul Hoffman, NCSU; Geoff Greene, ORNL; Takeyaeu Kito, LANL; Michael Kohl, Hampton University; Wolfgang Korsch, University of Kentucky

\section{Graduate ANd Postdoctoral Advisors and Advisees}

Graduate advisor: Ralph Segel, Northwestern U.

Postdoctoral sponsor: Robert Burman, LANL.

Graduate advisees

Adam Degrush, Industry; Michael Betancourt, University College London; Julie Millane, MIT Lincoln Laboratory; Aaron Maschinot, Industry; Colton O’Connor, MIT; Elizabeth Beise, U. Md.; Jozeph

Comuzz, Industry; William Burger, U. Geneva; David Rowntree, Industry; Nikolas Gregory, Industry; Manouchehr Farkhondeh, DOE

Postdoctoral associates

Joseph Seele, Brookhaven National Laboratory; Renee Fatemi, University of Kentucky; James Maxwell, Jefferson Laboratory; Justin Stevens, Jefferson Laboratory; Shalev Gilad, MIT. 


\title{
Evgeni P. Tsentalovich
}

\author{
Principal Research Scientist \\ MIT-Bates Linear Accelerator Center \\ Massachusetts Institute of Technology
}

\section{EDUCATION:}

$\begin{array}{llll}1982 & \text { B.Sc. } & \text { Physics } & \text { Novosibirsk University, Russia } \\ 1990 & \text { Ph.D. } & \text { Physics } & \text { Novosibirsk University, Russia }\end{array}$

\section{Professional EXPERIENCE:}

Principal Research Scientist

Group Leader (Polarized Injector and Targets), Bates Linear

Accelerator Center, MIT

Associate Group Leader, Bates Linear Accelerator Center, MIT

Research Scientist, Bates Linear Accelerator Center, MIT

Sponsored Research Staff, Bates Linear Accelerator Center, MIT

Postdoctoral Associate, Bates Linear Accelerator Center, MIT

Senior Researcher, Budker Institute for Nuclear Physics, Novosibirsk,

Russia

Researcher, BINP, Novosibirsk, Russia

Junior Researcher, BINP, Novosibirsk, Russia

Research Assistant, BINP, Novosibirsk, Russia
2011 - Present

2003 - Present

$2002-2003$

$1998-2011$

$1996-1997$

$1993-1996$

$1990-1993$

$1986-1990$

$1982-1986$

$1980-1982$

\section{SELECTED PUBLICATIONS:}

1. G. Dodson, M. Farkhondeh, E. Ihloff, E. Tsentalovich, "MIT-Bates polarized injector system", Workshop on Photocathodes for Polarized Electron Sources for Accelerators, Stanford, CA, September 1993, SLAC-432 p. 33 (1993).

2. M. Farkhondeh, G. Dodson, E. Ihloff, E. Tsentalovich, "Status of MIT-Bates polarized injector system", Proc. of the $12^{\text {th }}$ International Symposium on High Energy Spin Physics, Amsterdam, The Netherlands, World Scientific ISBN 981-02-3052-4, p. 680 (1996).

3. M. Farkhondeh, W, Franklin, E. Tsentalovich, T. Zwart, "Photoemission from strained GaAsP with a high power laser at MIT-Bates Linear Accelerator Center", Proc. of the $9^{\text {th }}$ International Workshop on Polarized Sources and Targets, Nashville, Indiana, 30 Sept.-4 Oct. 2001,World Scientific ISBN 981-02-4917-9, p.156 (2002). 
4. D. Cheever, M. Farkhondeh, W. Franklin, E. Tsentalovich, T. Zwart, "High Power Laser System for SHR", Proc. of $15^{\text {th }}$ International Spin Physics Symposium, Danvers, MA, AIP Conf. Proc. 675, 1019 (2002).

5. M. Farkhondeh, W. Franklin, E. Tsentalovich, T. Zwart, E. Ihloff, "MIT-Bates Polarized Source", Proc. of $15^{\text {th }}$ International Spin Physics Symposium, Danvers, MA, AIP Conf. Proc. 675, 1098 (2002).

6. M. Farkhondeh, W. Franklin, E. Tsentalovich, T. Zwart, E. Ihloff, "Operation of the MITBates Polarized Source for a High Average Current Storage Ring”, Proc. of $16^{\text {th }}$ International Spin Physics Symposium, Trieste, Italy, AIP Conf. Proc. 675, 897 (2004).

7. E. Tsentalovich, D. Barkhuff, J. Chen, G. Dodson, M. Farkhondeh, W. Franklin, E. Ihloff, F. Kaertner, C. Tschalaer, B. Yang. T. Zwart, "Development of a Polarized Electron Source for the MIT-Bates Accelerator Complex”, Nucl. Inst. And Meth. A582, 413 (2007).

8. E. Tsentalovich, "Polarized Source for eRHIC", Proc. of $12^{\text {th }}$ International Workshop on Polarized Sources, Targets and Polarimetry, Upton, NY, AIP Conf. Proc. 980, p.79 (2008).

9. E. Tsentalovich, "High Intensity Polarized Electron Gun Studies at MIT-Bates", Proc. of $18^{\text {th }}$ International Spin Physics Symposium SPIN2008, Charlottesville, VA, AIP Conf. Proc. 1149, 997 (2008).

10. E. Tsentalovich, "Status of High Intensity Polarized Electron Gun Project at MIT-Bates", Proc. Of $14^{\text {th }}$ International Workshop on Polarized Sources, Target and Polarimetry, St. Petersburg, Russia, eds. K. Grigoryev, P. Kravtsov and A. Vasilyev, ISBN 978-5-86763-282-3, p. 29 (2011).

\section{SYNERGiSTIC ACTIVITIES:}

None

\section{COllaborators and Co-editors}

Ricardo Alarcon, Arizona State University; John Calarco, University of New Hampshire; Haiyan Gao, Duke University; Michael Kohl, Hampton University; Michael Tiunov, Budker Institute for Nuclear Physics, Novosibirsk, Russia; Steven Williamson, University of Illinois

\section{Graduate ANd Postdoctoral Advisors ANd Advisees}

Graduate and Postdoctoral advisor: Stanislav Popov, Budker Institute Graduate and postdoctoral advisees: none 


\section{Appendix 2 \\ Current and Pending Support}

\section{Robert P. Redwine}

\section{Current Support}

Robert Redwine is supported under Task J, Hadronic Physics Group, by grant DE-FG0294ER40818 from the Department of Energy. This research group will receive funding of $\$ 3,062,000$ for the budget period 11/1/2015 - 10/31/2016. As a member and leader of the group, Professor Redwine will receive 0.5 months summer salary as well as support for a research scientist and 2 graduate students, travel and other research costs totaling approximately $\$ 400,000$. A renewal proposal for this grant will be submitted in 2016 that would continue this level of support.

Professor Redwine is also Director of the Bates Research and Engineering Center, which is funded as Task L under this same DOE grant for \$2,032,000 covering the same budget period $11 / 1 / 2015-10 / 31 / 2016$. Dr. Tsentalovich is partially supported on Task L, at the level of 0.6 man-years of effort for the period 11/1/2015 - 10/31/2016. A renewal proposal for this grant will be submitted in 2016 that would continue partial support of Dr. Tsentalovich.

As director at Bates, Professor Redwine is PI for a number of grants that support research activities there for which he receives no support and has 0 person-months:

Department of Energy, "High Intensity Polarized Gun” (DOE Award DE-SC0008741) $\$ 888,0008 / 15 / 2012-8 / 14 / 2016$. Dr. Tsentalovich expects to take 0.4 man-years of support for the period 8/15/2015 - 8/14/2016. We anticipate a carry-forward amount of $\$ n n n, n n n$ as of 8/14/16.

ProTom International, "MIT-ProTom Generation 2 Collaboration Year 2"; \$356,000; $1 / 1 / 16$ - 12/31/16. This is a project to develop a cyclotron and associated systems for proton beam therapy. Dr. Tsentalovich takes no support from this award.

\section{Pending Support}

As director at Bates, Professor Redwine is PI for proposals to support research activities there for which he receives no support and has 0 person-months:

Department of Energy, "High Intensity Polarized Gun" (this proposal) \$278,000 for the period $8 / 15 / 2016-8 / 14 / 2017$. If this proposal is approved, Dr. Tsentalovich will redirect a portion of his effort from Task L, at 4.8 months for 8/15/2016-8/14/2017. 


\section{Appendix 3}

\section{References}

1. R.Alley, H. Aoyagi, J. Clendenin, J. Frisch, C. Garden, E. Hoyt, R. Kirby, L. Klaisner, A. Kulikov, R. Miller, G. Mulhollan, C. Prescott, P. Sáez, D. Schultz, H. Tang, J. Turner, K. Witte, M. Woods, A. D. Yeremian, M. Zolotorev, The Stanford Linear Accelerator Polarized Electron Source, Nucl Instr. and Meth. A365, p.1-27 (1995).

2. K.Aulenbacher. Ch. Nachtigall, H. G. Andresen, J. Bermuth, Th. Dombo, P. Drescher, H. Euteneuer, H. Fischer, D. v. Harrach, P. Hartmann, J. Hoffmann, P. Jennewein, K. H. Kaiser, S. Köbis, H. J. Kreidel, J.Langbein, M. Petri, S. Plützer, E. Reichert, M. Schemies, H. -J. Schöpe, K. -H. Steffens, M. Steigerwald, H. Trautner and Th. Weis, The MAMI Source of Polarized Electrons, Nucl. Instr. and Meth. A391, p.498-506 (1997).

3. M.J.J.van den Putte, C. W. de Jager, B. L. Militsyn, Yu. M. Shatunov, Yu. F. Tokarev, Photocathode Lifetime Improvement by Using a Pulsed High Voltage on the Photocathode Gun of the Polarized Electron Source at NIKHEF , Nucl. Instr. and Meth. A406, p.50-52 (1998).

4. J.Grames, P.Adderley, M.Baylac, J.Clark, A.Day, J.Hansknecht, M.Poelker, M.Stutzman, Status of the Jefferson Lab Polarized Beam Physics Program and Preparations for the Upcoming Parity Experiments, Proc. of 15th Spin Ph. Symp., Danvers, AIP Conf. Proc. 675, p. 1047-1052 (2002).

5. Wolther von Drachenfels, Frank Frommberger, Michael Gowin, Wolfgang Hillert, Markus Hoffmann, Berthold Neff, The Polarized Electron Source at ELSA, Proc. of 15th Spin Ph. Symp., Danvers, AIP Conf. Proc. 675, p. 1053-1057 (2002).

6, E.Tsentalovich, D. Barkhuff, J. Chen, G. Dodson, M. Farkhondeh, W. Franklin, E. Ihloff, F. Kaertner, C. Tschalaer, B. Yang, T. Zwart, Development of a Polarized Electron Source for the MIT-Bates Linear Accelerator Center, Nucl. Instr. and Meth. A582, p.413-428 (2007).

7. Y.Poltoratska, R.Barday, U.Bonnes, M.Brunken, C.Eckart. R.Eichhorn, J.Enders, C.Hebler, C.Ingenhaag, W.F.O.Muller, M.Platz, M.Roth, B.Steiner, M.Wagner and T.Weiland, Status Report of the Darmstadt Polarized Electron Injector, Proc. of 18th Spin Ph. Symp., Charlottesville, AIP Conf. Proc. 1149, p. 983-986 (2009).

8. V.Ptitsyn, From HERA To Future Electron-Ion Colliders, Proc. of the Particle Accelerator Conference, p.1927-1931 (2007). 
9. M. Poelker, P. Adderley, J. Brittian, J. Clark, J. Grames, J. Hansknecht, J. McCarter, M.L. Stutzman, R. Suleiman, K. Surles-Law, High Intensity Polarized Electron Sources, Proc. of 12th Intern. PST Workshop, Upton, AIP Conf. Proc. 980, p.73-78 (2007).

10. R.Barday and K.Aulenbacher, Polarized Electron Source Operation at Average Currents of Several Milliamperes, Proc. of 17th Spin Ph. Symp., Kyoto, AIP Conf. Proc. 915, p.1019-1024 (2006).

11. E.Tsentalovich, Polarized Source For eRHIC, Proc. of 12th Intern. PST Workshop, Upton, AIP Conf. Proc. 980, p.79-84 (2007).

12. E.Tsentalovich, High Intensity Polarized Electron Studies at MIT-Bates, Proc. of 18th Spin Ph. Symp., Charlottesville, AIP Conf. Proc. 1149, p. 997-1001 (2009)

13. Michael A. Tiunov, Gennadi I. Kuznetsov and Marina A. Batazova, Simulation of High Current Electron and Ion Beam Dynamics for EBIS, Proc. of 18th Intern. Symp. on Electron Beam Ion Sources, Melville, New York, 2001, AIP Conf. Proc. 572, p.155-164 (2001).

14. E. Tsentalovich, "Status of High Intensity Polarized Electron Gun Project at MITBates", Proc. Of $14^{\text {th }}$ International Workshop on Polarized Sources, Target and Polarimetry, St. Petersburg, Russia, eds. K. Grigoryev, P. Kravtsov and A. Vasilyev, ISBN 978-5-86763-282-3, p. 29 (2011). 


\section{Appendix 4}

\section{Facilities and Other Resources}

The MIT-Bates Linear Accelerator Center has extensive existing infrastructure. Electric power, cooling water, air and nitrogen lines, and computer network access are available at the location where the apparatus is located. The EPICS control system is running at Bates, allowing easy development of the control elements for the beam line.

A high power diode laser equipped with a controller was purchased in Phase 1 of the project. Bates also has a large assortment of optical accessories. Other equipment purchased in Phase 1 that will be used in this project includes a laser power meter, a Fluorinert-compatible chiller, a gate valve and magnetically-coupled vacuum manipulators.

The Bates machine shop is equipped with programmable two-axis milling machines with a manual third axis. Welding and polishing equipment is available as well.

Vacuum equipment available at Bates includes roughing pumps and helium leak detectors.

The Laboratory for Nuclear Science Central Facility provides the administrative infrastructure and support services for researchers in nuclear and particle physics. These administrative functions include personnel, travel, fiscal, property and general services. These activities are organized so that the laboratory can most efficiently support the particular research activities pursued in the Laboratory. The financial support for these services is provided through an administrative allocation applied to all activities administered by the laboratory. It is applied to the Modified Total Direct Costs (MTDC) (which excludes equipment and tuition) and carries no Facilities and Administration (F\&A) overhead charge. The administrative allocation rate as of July 1, 2015 is 7.6\% for salaries and 0.6\% for materials and services. These rates are evaluated yearly and are approved by the Research Group Leaders in the Laboratory and by the Office of Cost Analysis within the Office of Sponsored Programs of MIT.

LNS manages four service centers on a no-gain, no-loss basis. One of these, the Bates Computing Services Center, provides networking, security, email and file service as well as software and hardware support for research at Bates. The activities of the Service Center are supported through an allocation based on the MTDC of the Bates research activities. As of July 1,2015 , the Bates rate is $10.0 \%$. The service center rates are approved yearly by the Laboratory Research Group Leaders and the Office of Cost Analysis within the Office of Sponsored Programs. 


\section{Appendix 5 Equipment}

The following equipment is already available for this project and is located at the testing site:

1. Gun chamber, tested.

2. Preparation chamber, tested.

3. Load-lock chamber, tested.

4. Beam line, tested.

5. Beam dump, tested.

6. Diode laser $(\lambda=805 \mathrm{~nm}, \mathrm{Pmax}=45 \mathrm{~W})$.

7. $150 \mathrm{kV}$ power supply.

8. Power supplies and control electronics for beam line elements.

9. Fluorinert-compatible chiller $1 / 4 \mathrm{HP}$ with cooling capacity of $800 \mathrm{~W}$ at $20^{\circ} \mathrm{C}$ and controllable flow rate up to $15.5 \mathrm{lpm}$. 


\section{Appendix 6 \\ Data Management Plan}

Data collected with the instrument constructed with funding from this proposal will be made available in peer-reviewed journals and conference proceedings. We also plan to make use of DSpace (http://dspace.mit.edu/) to upload additional information, such as simulation results, CAD models, engineering drawings and publications. DSpace@MIT is maintained by the MIT Libraries. The content is open-access and searchable. DSpace@MIT is part of the larger DSpace community, a world-wide group of developers, researchers and users of this digital repository system. 